\title{
Desafios da participação e da descentralização na gestão de políticas culturais nas cidades
}

\author{
Desafíos de la participación y la descentralización \\ en la gestión de políticas culturales en las ciudades
}

\section{Participation and decentralization as management's principles in cultural policies in Bogotá}

\author{
Monica Cristina Moreno-Cubillos'
}

\author{
Palavras chave: \\ Participação \\ Descentralização \\ Políticas Culturais \\ Governança urbana \\ Bogotá
}

\section{Resumo:}

Analisa-se a inserção da participação e da descentralização como princípios para a gestão das políticas culturais, tomando como exemplo a capital da Colômbia, mediante o levantamento documental de material normativo sobre políticas culturais nesse país e o estudo de caso intrínseco através dos depoimentos de diferentes sujeitos, dentro e fora da institucionalidade, que refletem sobre os mecanismos estabelecidos especificamente em Bogotá. Para tal fim, exploramse os principais traços da governança urbana no período neoliberal e as particularidades dessa cidade, revisa-se a incorporação dos princípios de participação e descentralização nas políticas culturais e nas diretrizes para a gestão cultural da Colômbia e discute-se a forma como estes se materializam nas políticas culturais da cidade, visibilizando algumas fraquezas relacionadas com o desenho do sistema, a capacidade institucional e dos agentes culturais que agem nos espaços, a articulação entre diversos canais de participação e a incidência dos acordos em decisões como distribuição de recursos, entre outros. Finalmente, apontam-se alguns desafios em três perspectivas: a integração dos públicos nas discussões, o grau de autonomia dos espaços, e a necessidade de debater a categoria 'cultura' como ponto de partida para a definição das linhas de intervenção. 
Resumen:

Se analiza la inserción de la participación y la descentralización como principios para la gestión de las políticas culturales tomando como ejemplo la capital de Colombia mediante el levantamiento documental de material normativo sobre políticas culturales en ese país y el estudio de caso intrínseco a través de los testimonios de diferentes sujetos dentro y fuera de la institucionalidad que reflexionan sobre los mecanismos establecidos específicamente en Bogotá. Para esto, se exploran los principales trazos de la gobernanza urbana en el periodo neoliberal y las particularidades de esa ciudad, se revisan la incorporación de los principios de participación y descentralización en las políticas culturales y en las directrices para la gestión cultural de Colombia, y se discute la forma como estos se materializan en las políticas culturales de la ciudad visibilizando algunas debilidades relacionadas con el diseño del sistema, la capacidad institucional y de los agentes culturales que actúan en los espacios, la articulación entre diversos canales de participación y la incidencia de los acuerdos en decisiones como distribución de recursos, entre otros. Finalmente, se apuntan algunos desafíos en tres perspectivas: la integración de los públicos en las discusiones, el grado de autonomía de los espacios y la necesidad de debatir la categoría 'cultura' como punto de partida para la definición de las líneas de intervención.
Palabras clave:

Participación

Descentralización

Políticas Culturales

Gobernanza urbana

Bogotá

\section{Keywords:}

Participation

Descentralization

Cultural Policies

Urban governance

Bogota

\section{Abstract:}

We analyze the insertion of participation and decentralization as management's principles of cultural policies taking as an example the capital of Colombia through the documentary survey of normative material on cultural policies in that country and the intrinsic case study through the testimonies of different subjects inside and outside the institutions that reflect on the mechanisms established specifically in Bogotá. To this end, we explore the main features of urban governance in the neoliberal period and the particularities of that city, we review the incorporation of participation and decentralization as principles of cultural policies and guidelines for cultural management in Colombia, and we discuss how they materialize in the cultural policies of the city, highlighting some weaknesses related to the design of the system, the institutional and the cultural agents' capacity that act in the spaces, the articulation between diverse channels of participation and the incidence of the agreements in decisions like distribution of resources, among others. Finally, we point out some challenges in three perspectives: the integration of the public in the discussions, the degree of autonomy of the spaces and the need to debate the category 'culture' as a starting point for the definition of the lines of intervention. 


\section{Desafios da participação \\ e da descentralização na gestão de políticas culturais nas cidades}

\section{Introdução}

A imposição das reformas neoliberais nos países da América Latina trouxe a aplicação de mecanismos como controle social, rendição de contas, desregulamentação, parcerias público-privadas, profissionalização do serviço público, participação, descentralização, entre outros, para a gestão dos assuntos públicos em diferentes campos sociais e níveis de governo, que foram introduzidos paulatinamente sob as demandas que também fizeram os movimentos sociais advogando por uma forma de aceder às decisões públicas.

Esta situação não é alheia para as cidades onde se manifestam nitidamente os efeitos sociais provocados pelo sistema capitalista de produção que, em seu estágio atual, agudiza questões como pobreza, desigualdade, informalidade, discriminação, marginalização, iniquidade no acesso aos serviços e equipamentos urbanos, segregação, além de outras, sendo objeto de discussão nas políticas públicas urbanas. Neste contexto, as políticas culturais têm sido usadas como ferramentas de ação que visam à coesão e a inclusão social de grupos que historicamente foram mais afetados.

Com este panorama, propõe-se analisar a inserção da participação e da descentralização como princípios para a gestão das políticas culturais especificamente em Bogotá mediante o estudo dos documentos oficiais que guiam a implementação das linhas de intervenção em confronto com depoimentos de representantes (dentro e fora da institucionalidade) dos espaços de concertação abertos na cidade para acessar às decisões sobre formulação, implementação e avaliação de políticas e projetos neste campo. Por conseguinte, os procedimentos metodológicos utilizados são o levantamento documental e o estudo de caso intrínseco que permitem a coleta de material normativo sobre políticas culturais na Colômbia e em Bogotá (incluindo documentos oficiais de formulação e relatórios sobre o desenvolvimento deste campo na cidade), além de publicações resultantes dos processos de pesquisa e formulação de políticas culturais disponíveis nas bibliotecas públicas da cidade,que reúnem as opiniões de pesquisadores, acadêmicos, centros de pesquisa e estudos, e funcionários públicos de altos níveis dentro do governo municipal, mostrando um leque de visões e posições.

Desta forma, inicialmente se exploram os principais traços da governança urbana no período neoliberal, especificando - caso de Bogotá; depois se revisa a incorporação dos princípios de participação e descentralização nas políticas culturais e em especial nas diretrizes para a gestão cultural da Colômbia; em seguida se discute a forma como estes se materializam nas políticas culturais da cidade visibilizando algumas fraquezas; e finalmente se mencionam três desafios que deveriam se considerar em novos processos de formulação de políticas culturais na cidade.

\section{A modalidade de governança urbana no neoliberalismo}

A crise de superprodução e fiscal de 1970 pôs em xeque o Estado de Bem-Estar, levando a que o Banco Mundial e o Fundo Monetário Internacional (principalmente) reassumissem e promovessem as ideias da primazia do livre mercado como regulador da vida social registradas no Consenso de Washington em 1989. Ainda quando a Europa e os Estados Unidos as introduziram na atuação de seus governos, os países do Terceiro Mundo as adotaram com maior rigor mediante a redução dos gastos públicos sociais, 
prestando atenção àqueles gerados por causa do funcionamento do aparato estatal.

Nessa conjuntura surge o paradigma administrativo conhecido como Novo Gerencialismo Público (NGP) que tem como noção implícita que as organizações públicas devem se gerenciar como negócios para alcançar a competitividade (ROBINSON, 2015; KAPUCU, 2007) sob a premissa de que um governo eficiente custa menos. Portanto, as principais estratégias que se demandam na gestão pública estão relacionadas com cortes no orçamento das organizações, privatizações, separação entre a política e a administração, subcontratação, imposição de taxas de utilização, introdução do conceito de cliente, concorrência, liberdade para gerir (desenho de incentivos), descentralização, medição do desempenho, melhora dos processos contábeis e da gestão financeira, auditorias, planejamento estratégico, gestão da mudança, uso de tecnologias de informação, racionalização das competências e das estruturas administrativas, análise e avaliação de políticas, e democratização e participação dos cidadãos nas decisões (GRUENING, 2001).

Nas cidades, a adoção dos princípios neoliberais e a implementação do NGP se evidencia no fomento de políticas de desenvolvimento econômico que invocam o estabelecimento de parcerias público-privadas, o aumento de programas para atenuar a exclusão social (exigindo uma maior atenção no setor cultural), o incentivo de novas formas de coordenação intersetorial e intergovernamental" (BRENNER \& THEODORE, 2002; HARVEY, 2007; JANOSCHKA \& HIDALGO DATTWYLER, 2014) sem esquecer as ações para o impulso e o fortalecimento do controle social e a participação cidadã que abrange a aplicação de mecanismos como os processos de consulta da população afetada negativamente pelas decisões públicas, o estabelecimento de estruturas consultivas e deliberativas e, em alguns casos, a transferência das funções do Estado para as organizações e instituições da sociedade civil (RIVIĖRE D'ARC, 1993; LÓPEZ MOYA, 2010), ou para níveis de governo com presença e autoridade em uma área definida ou parte específica do território, também conhecida como descentralização (LEVY, 1993; SPINK, 1993).

Assim, a participação e a descentralização aparecem imbricadas na gestão pública urbana como parte das estratégias de desenvolvimento econômico e social que, no discurso, visam redefinir as relações de poder, tornando os efeitos dos programas duráveis no longo prazo (SPINK, 1993) e aumentando a intervenção dos cidadãos na tomada de decisões para fortalecer a democracia local (LEVY, 1993). Contudo, na prática, observam-se como estes princípios terminam servindo a outros interesses que despolitizam a atuação dos governos municipais mediante modelos técnicos e gerencialistas, e aumentam a concorrência dos governos e entidades territoriais por atrair maiores investimentos, entre outros efeitos (RESTREPO BOTERO, 2003), restringindo os conflitos e lutas pelo poder em componentes administrativos.

Bogotá, capital da Colômbia, não é indiferente a estas práticas, as quais foram introduzidas com maior vigor desde a década de 1990, momento de abertura democrática visto que coincide com a eleição de prefeitos municipais no país estratégia instaurada em 1988 como um mecanismo para descentralizar administrativamente a estrutura pública - e a reforma à Constituição Política em 1991.

Algumas transformações experimentadas na capital se relacionam com o início do processo de administração mista de serviços públicos permitindo a entrada de capital privado e racionalizando os benefícios econômicos, a venda de empresas públicas, a descentralização do serviço básico de vigilância mediante Comandos de Atenção Imediata da polícia nos bairros com maiores índices 
de insegurança, o saneamento das finanças, a reforma à norma administrativa e a modernização da estrutura pública municipal (REDACCIÓN BOGOTÁ, 2015; CÁRDENAS S. et. al., 2007); além da criação e formalização de diferentes canais, programas e instrumentos de participação cidadã e descentralização como os Quadros de Gestão Locall" (QGL), os Conselhos de Planejamento LocaIV (CPL) e o Sistema Distrital de Cultura com todos seus espaços de concertação $\vee$, ou a elaboração de planos zonais ${ }^{\mathrm{Vl}}$ e programas como 'obras com saldo pedagógico'VII (RESTREPO BOTERO, 2003).

Por conseguinte, não é casualidade que os planos de governo das últimas duas décadas estabeleçam dentro de seus princípios de ação - com diferentes graus de importância - a participação, o controle social e a descentralização como forma de legitimar suas propostas e ações.

\section{O NGP e as políticas culturais}

Os princípios de participação e descentralização nas políticas culturais têm sido tema de discussão de longa data. Como exemplo disso, na Conferência Mundial sobre Políticas Culturais (MONDIACULT) de 1982, convocada pela Organização das Nações Unidas para a Educação, a Ciência e a Cultura (UNESCO), incorporaram-se estas categorias com ligações diretas na relação cultura e democracia. Deste modo, estabeleceu-se que as manifestações culturais não podem ser privilégio das elites nem na produção nem nos benefícios, razão pela qual é necessário descentralizar a vida cultural e as instituições que agem no campo (geográfica e administrativamente), garantindo a participação de todos os indivíduos (UNESCO, 1982).

Sob esta perspectiva se constroem os principais paradigmas nas políticas culturais tradicionais: a democratização cultural e a democracia cultural que, ainda apresentando-se como opostas, discorrem sobre estes dois elementos.

A democratização cultural tenta devolver ao povo a possibilidade de eleger quais obras ou atividades culturais prefere e, por tanto, quais artistas devem ser apoiados para assim facilitar a todos o acesso às criações artísticas e estéticas (VIDAL-BENEYTO, 1981) sob o postulado que para produzir adesão é suficiente o encontro público-obra. Em consequência, as políticas culturais que seguem este paradigma dão prioridade aos profissionais, à descentralização dos grandes equipamentos e à redução dos preços ou a gratuidade completa de eventos que suponham a alteração das desigualdades no ingresso (BOTELHO, 2001).

A democracia cultural "tem por princípio favorecer a expressão de subculturas particulares e fornecer aos excluídos da cultura tradicional os meios de desenvolvimento para eles mesmos se cultivarem, segundo suas próprias necessidades e exigências" (BOTELHO, 2001, p. 24) defendendo a coexistência das múltiplas culturas em uma mesma sociedade, propiciando seu desenvolvimento autônomo e relações igualitárias para a participação de cada pessoa na sua cultura e na cultura dos outros, dado que se reconhece que não há uma cultura legítima e que as políticas culturais não devem difundir só a cultura hegemônica, mas promover o desenvolvimento de todas (GARCÍA CANCLINI, 1987). Com tal característica, as políticas culturais orientadas por este paradigma visam "estimular a ação coletiva através de uma participação organizada, autogerida, reunindo as mais diversas iniciativas (de todos os grupos, no político, no social, no recreativo, etc.)"VIII (GARCÍA CANCLINI, 1987, p. 51, tradução própria) que supõe dar voz a todos os grupos presentes no território.

Contudo, ainda quando os movimentos sociais exigiram esta forma de ação, as reformas neoliberais permeiam e se valem destas reivindicações para legiti- 
mar interesses e objetivos da economia de mercado dando como resultado políticas culturais instrumentais "ante os possíveis efeitos de processos como a homogeneização cultural, o aumento das desigualdades sociais ou a dissolução das identidades coletivas"IX (ZAMORANO et. al., 2014, p. 23, tradução própria) que assumem os princípios do NGP para a implementação e gestão fazendo com que a descentralização se traduza em desregulamentação e a participação em transferência de responsabilidades para a sociedade civil. Em palavras de García Canclini (2008)

[...] transferir a iniciativa à sociedade civil quer dizer, para o discurso neoconservador, concentrar o poder em empresas privadas monopólicas. $\mathrm{O}$ desinteresse do Estado em que a informação, a arte e as comunicações sejam serviços públicos faz com que se convertam preferencialmente em mercadorias e só sejam acessíveis a setores privilegiados. Nessa conjuntura a fragmentação dos públicos, fomentada pela diversificação das ofertas, reduz a expansão dos bens simbólicos. De fato, o que se produz é uma segmentação desigual dos consumos (p. 371, grifo do autor).

Na Colômbia, a descentralização e a participação também têm sido categorias centrais na formulação de políticas culturais que a partir do primeiro plano cultural nacional em 1974 incluiu medidas relacionadas com a descentralização, a incorporação das crianças e dos jovens como núcleo e população objeto da política cultural, o estímulo à criação e à participação dos criadores e o financiamento. Daqui em diante, os planos nacionais seguiram discutindo estas categorias, as quais seriam finalmente materializadas com a criação do Sistema Nacional de Cultura e Desenvolvimento Institucional composto por conselhos nacional, regionais, departamentais e municipais constituídos como organismos assessores para a formulação de políticas culturais direcionando o estabelecimento de ações que contribuíssem ao desenvolvimento cultural do país e o acesso da comunidade aos bens e serviços culturais (MENA LOZANO; HERRERA CAMPILLO, 1994).

Contudo, mediante a Lei 397 de 1997 ou Lei Geral de Cultura a participação e a descentralização se posicionam como princípios reitores para o funcionamento do Sistema Nacional de Cultura (COLOMBIA, 1997). Apesar disso, um vazio que se evidencia nesta normativa é a falta de definição destas categorias que deixa aberta sua interpretação e a forma de ser implementada.

Desta forma, observa-se como a descentralização e a participação são princípios impulsados nas políticas culturais tanto pelos organismos internacionais quanto pelos movimentos sociais com distintos objetivos, mas articulados no mesmo discurso que dilui e encobre as tensões e contradições que sua implementação representa.

\section{Desencontros na participação e na descentralização nas políticas culturais em Bogotá}

Ainda quando em Bogotá se desenvolveram múltiplas iniciativas em matéria cultural, só até inícios do século XXI foram publicadas as primeiras políticas culturais formais que seriam objeto de revisão e atualização uma vez terminado o prazo de ação definido dando origem a um segundo documento oficial. Destaca-se que as duas políticas culturais foram construídas de forma participativa nos espaços de concertação abertos pelo Sistema Distrital de Cultura que segue a forma do Sistema Nacional, em menor escala territorial.

As primeiras políticas culturais 'Bogotá en acción cultural 2001-2004' são a resposta à demanda dos artistas, criadores e gestores 
culturais por um documento elaborado conjuntamente entre o governo e suas institucionalidades, os representantes do setor e outros sujeitos interessados no campo cultural que não deram conta unicamente da visão e interesses do Prefeito de turno, mas que definissem regras de longo prazo para a gestão e a promoção artística e cultural no nível municipal e local (RODRÍGUEZ ROMERO, 1999; REPRESENTANTE DE LOS ARTISTAS AL CONSEJO DISTRITAL DE CULTURA, 1999; CORPORACIÓN ESCUELA DE FORMACIÓN CIUDADANOS SIGLO XXI, 2000).

Em vista disso, partindo de preceitos como a cultura como um valor universal; a legitimação da pluralidade e a diversidade cultural; o estímulo à produção, gestão e criação cultural; o apoio mediante a educação, difusão e pesquisa; a afirmação da identidade e proteção das tradições das comunidades negras e indígenas; a defesa das pessoas com deficiência e o povo ROM; a democratização do acesso a bens e serviços culturais; a difusão e apoio às manifestações culturais (incluídas as minorias étnicas); a recuperação da importância do público; a aplicação das recomendações da UNESCO para a salvaguarda da cultura tradicional e popular; definem-se as sete linhas temáticas para a intervenção (organização, formação e capacitação, patrimônio cultural, fomento à arte e à cultura, promoção e divulgação da cultura, infraestrutura cultural e pesquisa) conduzidas por cinco estratégias fundamentais: o controle social, o financiamento, a comunicação, a participação e a descentralização (COMITÉ DE POLÍTICAS CULTURALES, 2003).

Neste caso, a descentralização é entendida no político como os espaços para a tomada de decisões, no administrativo, onde as localidade ${ }^{\mathrm{X}}$ ficam responsáveis do cultural e da procura de níveis de complementaridade para potencializar a intervenção, no orçamental para a destinação de recursos a serem executados pelas localidades seguindo critérios claramente estabelecidos pelo Instituto Distrital de Cultura e Turismo (IDCT) ${ }^{\mathrm{XI}}$, e no planejamento a concertação da política cultural como parte do Plano do Governo da cidade. Por sua parte, a participação abrangeria a cooperação na formulação, implementação dos processos e projetos locais e do Plano do Governo geral de Bogotá, e no controle social do investimento dos recursos públicos destinados ao desenvolvimento cultural (COMITÉ DE POLÍTICAS CULTURALES, 2003).

Assim, a introdução destas estratégias tem origem numa reivindicação dos sujeitos que colaboraram na formulação do documento. No entanto, é importante mencionar que o Estado as aprova utilizando certa retórica, enquanto os movimentos sociais se apropriam do sentido delas com outro tipo de significação (OCHOA GAUTIER, 2003).

De forma pontual, sobre a descentralização, o processo implica a designação de gestores locais vinculados ao IDCT os quais seriam o que "o diretor do instituto é à realidade centralizada da cidade, isto é, o gerente deve ser pensado dentro de um processo de descentralização como gerente ou reitor ou secretário de cultura da localidade"XII (LIZARAZO, 1999, p. 64-65, tradução própria) cumprindo funções como: exercer a direção da política cultural da localidade, conhecer a localidade em matéria cultural, realizar sua gestão com base no plano de ação de cultura no nível local sob as orientações do IDCT, gerenciar a execução do plano de ação, representar o IDCT nas suas responsabilidades locais e avaliar o processo local permanentemente (LIZARAZO, 1999).

Por sua parte, para os movimentos sociais, no processo de descentralização é necessária "a geração de organização artística e cultural pela base e particularmente por áreas e disciplinas artísticas, reafirmando que a experiência vivida na localidade é possível e desejável de replicar para fortalecer os Sistemas Locais de Cultura, entre outros"XIII (CORPORACIÓN ESCUELA DE FORMACIÓN CIUDADANOS SIGLO XXI, 2000, p. 3, tradução própria). 
Por conseguinte, é claro que para a institucionalidade o processo de descentralização não implica a autonomia das localidades visto que está restrita aos guias dados desde a Prefeitura em matéria cultural representada pelo IDCT. Este ponto é reafirmado quando se expressa que a descentralização orçamental será conseguida sempre e quando as localidades sigam os 'critérios claramente estabelecidos pelo IDCT'. Aliás, é evidente a forma como as discussões nas localidades são dirigidas seguindo os padrões do setor central, reduzindo-se aos temas que a institucionalidade tem o interesse de debater, mas excluindo outros que são importantes para os grupos. Neste sentido, um dos Conselheiros das localidades, em 2003, expressa:

[...] consideramos que há uma forte homogeneização sob um único modelo de políticas culturais, perdendo a possibilidade de construir a partir dos ritmos e peculiaridades de cada localidade seus próprios processos. É dizer, queremos homogeneizar, queremos trabalhar sob um único esquema dentro do Distrito e o que foi mostrado é que cada localidade tem seu próprio ritmo, uma particularidade e desenvolvimento que torna necessário construir com essa realidade particular ${ }^{\mathrm{XIV}}$ (RAMÍREZ, 2003, p. 98, tradução própria).

O segundo documento de políticas culturais 'Políticas Culturales Distritales 2004-2016' foi igualmente elaborado no seio do Sistema Distrital de Cultura sob a liderança do IDCT. Neste se reorganiza a intervenção dividida em quatro eixos e doze linhas de ação (Tabela 1) enfrentando os principais problemas identificados nos diagnósticos. Esta se orienta por oito princípios: a interculturalidade, a concertação, a criatividade, a sustentabilidade, a articulação, o valor do público, a descentralização e a participação.

\begin{tabular}{|l|c|}
\hline \multicolumn{1}{|c|}{ Eixo } & Linha de ação \\
\hline \multirow{4}{*}{ Legislativo } & Desenvolvimento legislativo \\
\hline \multirow{4}{*}{$\begin{array}{l}\text { Organizacional } \\
\text { e da informação }\end{array}$} & Relações estratégicas \\
\cline { 2 - 2 } & Organização intra-setorial \\
\cline { 2 - 2 } & Planejamento do Sistema Distrital de Cultura \\
\cline { 2 - 2 } & Organizações sociais e espaços de concertação \\
\hline \multirow{3}{*}{$\begin{array}{l}\text { Processos culturais, artísticos } \\
\text { e do patrimônio }\end{array}$} & Pesquisa sobre a cultura \\
\cline { 2 - 2 } & Sistemas de informação \\
\cline { 2 - 2 } & Difusão e visibilização \\
\cline { 2 - 2 } & Planos concertados \\
\cline { 2 - 2 } & Fomento do campo \\
\cline { 2 - 2 } & Infraestrutura cultural \\
\hline
\end{tabular}

Tabela 1: Eixos e linhas de ação das Políticas Culturales Distritales 2004-2016 
Novamente a descentralização e a participação são consideradas princípios guias. A descentralização é definida como "a transferência de poder, recursos, funções e capacidade de decisão do centro para as unidades territoriais e no fortalecimento de infraestruturas e organizações locais que possam efetivamente desenvolver esse processo"xv (COMISIÓN DE POLÍTICAS CULTURALES, 2004, p. 63, tradução própria). A participação compreende a atuação ativa "nas decisões que os afetam e na vida econômica, política, administrativa e cultural da nação como um direito constitucional"XVI (COMISIÓN DE POLÍTICAS CULTURALES, 2004, p. 63, tradução própria). Ambas, outra vez, se materializam no Sistema Distrital de Cultura e seus espaços de concertação.

Ainda quando no diagnóstico o Sistema é posicionado como um dos mecanismos mais eficientes, reconhecem-se algumas deficiências que geram contradições para alcançar os objetivos de transferência de poder, fortalecimento das organizações locais e atuação nas decisões que afetam diferentes campos da vida social. As fraquezas podem ser agrupadas nas seguintes categorias: 1) desenho do sistema, 2) capacidade institucional e dos agentes culturais, 3) articulação e 4) incidência dos acordos (OBSERVATORIO DE CULTURAS \& DIRECCIÓN DE ARTE CULTURA Y PATRIMONIO, 2014).

Sobre o desenho do modelo se encontra que este é percebido como fechado com limites na representatividade dos conselheiros. Neste aspecto, tem-se constatado como alguns conselheiros 1) são designados por um número mínimo de eleitores o que resulta na busca de interesses individuais por desconhecimento das demandas do grupo que representa (RUBIANO PINILLA, 2009); 2) não consultam outros sujeitos para a tomada de posição refletindo suas aspirações particulares visto que o acesso ao sistema provê informação preferencial e relacionamento estratégico (OBSERVATORIO DE CULTURAS \& DIRECCIÓN DE ARTE CULTURA Y PATRIMONIO, 2014); e 3) quase $50 \%$ dos conselheiros distritais têm sido reelegidos desde o início com o que o posicionamento de interesses se perpetua.

Aliás, o Sistema é um modelo de participação institucional, com dinâmicas de interação concretas, que não foi concebido como uma iniciativa dos cidadãos (ARIZA PORRAS, 2015; OBSERVATORIO DE CULTURAS \& DIRECCIÓN DE ARTE CULTURA Y PATRIMONIO, 2014; CORTÉS GÓMEZ, 2007), mas como uma opção que o Estado projetou para 'democratizar' a tomada de decisões no campo cultural as quais, na maioria dos casos, ficam presas em temas como a designação de recursos, a abertura de editais ou o concurso por bolsas (ARIZA PORRAS, 2015, p. 135).

Finalmente, apresenta-se uma situação paradoxal: por um lado, a participação no Sistema é estendida a diferentes grupos sociais e profissionais que têm interesse no campo cultural; contudo, os grupos têm se fraccionado populacional e setorialmente causando problemas de articulação dentro dos espaços, reforçando a tendência de favorecer interesses concretos (OBSERVATORIO DE CULTURAS \& DIRECCIÓN DE ARTE CULTURA Y PATRIMONIO, 2014). No mesmo sentido, esta forma de organização que induz à garantia dos direitos das minorias (indígenas, afro-colombianos, LGBTI, população idosa, crianças, etc.), pode levar à exclusão de grandes camadas de maiorias necessitadas que fiquem fora do enfoque populacional (FERRO PULIDO, 2013, p. 82). 
No relativo à capacidade institucional e dos agentes culturais existe um reconhecimento por parte da instituição líder (a SCRD antes IDCT) sobre a baixa capacidade para coordenar o Sistema; assim como a identificação de limitadas competências e capacidades por parte dos cidadãos e agentes culturais para participar da forma em que o Sistema requer, gerando problemas de interação e construção coletiva do público.

Um dos determinantes desta situação é a falta de acompanhamento e assessoria dos Escritórios de Planejamento das Prefeituras Locais para a formulação de projetos culturais e a entrega de informação necessária gerando desinteresse, afastamento e desmotivação para a apresentação de propostas (RAMÍREZ, 2003, p. 99). Além disso, às vezes, os Conselhos Locais de Cultura se comportam como instâncias fechadas que não admitem ou promovem consultas nem encontros com a cidadania, perdendo espaços para conhecer as necessidades da população e divulgar as políticas culturais, seus programas, projetos e resultados (RAMÍREZ, 2003). Isto se traduz em dificuldades no interior do Sistema, na apropriação dos espaços deliberativos por parte dos cidadãos (FERRO PULIDO, 2013, p. 82), e na interação dos conselheiros e a cidadania.

No referente à capacidade de articulação se observa uma baixa interlocução entre os Conselhos Locais de Cultura e outras instâncias de planejamento local como os CPL ou os QGL que faz com que as decisões tomadas em todos estes espaços não persigam os mesmos objetivos ou sejam até contraditórias, e que os cidadãos e, em alguns casos, as mesmas autoridades desconheçam os Conselhos Locais de Cultura como mecanismos para a participação e a construção das políticas culturais (RAMÍREZ, 2003).
Finalmente, as rupturas entre conselheiros e comunidade, e dos Conselhos com as outras instâncias de participação (FERRO PULIDO, 2013, p. 81) produz uma baixa incidência dos acordos e decisões para a execução da política cultural (OBSERVATORIO DE CULTURAS \& DIRECCIÓN DE ARTE CULTURA Y PATRIMONIO, 2014), ocasionando desconfiança nos processos de participação e na institucionalidade, levando a que as decisões fiquem em mãos dos Prefeitos das localidades e seus interesses. Como Bromberg (2003) aponta:

Em geral, apenas os atores estatais têm o poder de decidir, porque esse poder é atribuído a eles por lei. Os outros só têm o poder de influenciar. $\mathrm{Na}$ área da política cultural local, o Prefeito, o Conselho, o prefeito local, os UEL e, [...] - em um nível inferior - os Quadros de Gestão Local tomam decisões. [...] O prefeito local é aquele que toma as decisões sobre quais projetos são executados com um orçamento local. [...] Todas as outras instâncias e autoridades apenas exercem pressão sobre ele. Nem o QGL, nem o Conselho Local de Cultura, nem os Encontros Cidadãos tomam decisões relevantes ( $p$. 70 , tradução própria) ${ }^{\mathrm{XV} I}$.

\section{Alguns desafios para a implementação da participação e da descentralização nas políticas culturais}

É certo que as políticas culturais em Bogotá têm aberto canais de participação descentralizados, que dão a possibilidade a grupos de discutir questões relacionadas com o campo focalizadas nos territórios. Ainda quando é um Sistema inovador, suas fraquezas desestimulam a atuação dos sujeitos e limitam o alcance das decisões tomadas aí; ali- 
ás, dada a organização e regras para a entrada, o Sistema não representa as opiniões da maioria dos cidadãos, mas só daqueles que desenvolvem atividades artísticas ou culturais que, segundo os dados dos diagnósticos nos quais se fundamentam as políticas, representam $6 \%$ do total da população.

Em consequência, destacam-se três desafios a considerar na formulação de novas políticas culturais para a cidade.

O primeiro se relaciona com a integração das vozes dos 'consumidores' ou 'público' nos espaços de participação acabando com o enfoque que dá prioridade exclusivamente aos grupos oferentes para a formulação. Por uma parte, Durand (2001) expressa que esta questão se constitui como o 'lado faltante' para a formulação de políticas em cultura e a alocação de recursos no campo. Por outra parte, Bromberg (2003) aponta que a falta de caracterização de grupos e serviços que demandam práticas culturais origina formas muito distintas de interação, visto que não são os cidadãos 'público' que pedem os eventos ou os programas de formação, entre outros; mas são os 'provedores' os que estruturam o que se fornece e pedem os orçamentos e apoios.

O segundo desafio remete à revisão do grau real de autonomia dos espaços descentralizados sem que isso se traduza em falta de complementaridade, sinergias e articulações entre a SDCR, o Conselho Distrital de Cultura e os Conselhos Locais.

Finalmente, o terceiro se foca em chamar ao debate à definição, com todas as consequências que se derivam, da principal categoria objeto de intervenção, ou seja, 'cultura'. Quanto a isso, concorda-se com as considerações de Vich (2005) quando afirma que
[...] qualquer política cultural [...] que evite esse problema está destinada a se contentar com a gestão administrativa pura e necessária - e, na verdade, pode ser muito eficiente - mas não a libera de uma rede de cumplicidades que podem acabar levando-a à impossibilidade de gerar articulações mais criativas entre vários atores sociais (p. 274-275, tradução própria) ${ }^{\mathrm{XVIII}}$.

\section{Bibliografia}

ARIZA PORRAS, Angie Paola. Escenas y tras escenas de las políticas públicas en Bogotá: su incidencia en la consolidación y autonomía del campo teatral durante 2006 - 2012. Calle14: revista de investigación en el campo del arte, v. 10, n. 15, p. 124-137, 2015.

BOGOTÁ. Decreto 627, de 28 de diciembre de 2007. Por el cual se reforma el Sistema Distrital de Cultura y se establece el Sistema Distrital de Arte, Cultura y Patrimonio. Registro Distrital, Bogotá, D.C., n. 3902.

BOTELHO, Isaura. As dimensões da cultura e o lugar das políticas públicas. Revista São Paulo em Perspectiva, v. 15, n. 2, 2001.

BRENNER, Neil; THEODORE, Nik. Cities and the Geographies of 'Actually Existing Neoliberalism'. Antipode, Oxford, UK and Boston, USA, v. 34, n. 3, p. 349-379, 2002.

BROMBERG, Paul. Instancias de decisión para la definición de políticas para el sector cultural. In: BUSTOS, Marta, NADER; Zaquile; PEÑA, Adriana. (orgs.) Formar para la democracia. Políticas culturales en el Distrito Capital y sus localidades. Bogotá, D.C.: Alcaldía Mayor de Bogotá \& Instituto Distrital de Cultura y Turismo, 2003.

CÁRDENAS S., Jorge Hernán; JIMENEZ, Johana; BARRIGA, Jorge. Performance of Bogotá and city growth 1990-2007. Case study. Bogotá, D.C., 2007. 
COLOMBIA. Ley 397, de 7 de agosto de 1997. Por la cual se desarrollan los Artículos 70, 71 y 72 y demás Artículos concordantes de la Constitución Política y se dictan normas sobre patrimonio cultural, fomentos y estímulos a la cultura, se crea el Ministerio de la Cultura y se trasladan algunas dependencias. Diario oficial [de la República de Colombia], Bogotá, D.C., n. 43102.

COMISIÓN DE POLÍTICAS CULTURALES. Políticas Culturales Distritales 2004-2016. Bogotá, D.C.: Consejo Distrital de Cultura, Instituto Distrital de Cultura y Turismo \& Alcaldía Mayor de Bogotá, 2004.

COMITÉ DE POLÍTICAS CULTURALES. Políticas Culturales Distritales. Bogotá en acción cultural 2001-2004. In: BUSTOS, Marta. (org.) Documentos Distritales de Política Cultural (Serie Políticas Culturales). Bogotá, D.C.: Alcaldía Mayor de Bogotá \& Instituto Distrital de Cultura y Turismo, 2003.

CORPORACIÓN ESCUELA DE FORMACIÓN CIUDADANOS SIGLO XXI. Documento de Conclusiones del Foro sobre Cultura en Bogotá Año 2000. In: FORO SOBRE CULTURA EN BOGOTÁ, 2000, Bogotá, D.C.

CORTÉS GÓMEZ, Juan Alberto. Políticas culturales en Bogotá: Un análisis introspectivo frente a los límites y desafíos de la interculturalidad. 101 f. Disertación (Maestría en Estudios de la Cultura) - Área de Letras y Estudios Culturales, Universidad Andina Simón Bolívar - Sede Ecuador, Quito, 2007.

DURAND, José Carlos. Cultura como objeto de política pública. Revista São Paulo em Perspectiva, v. 15, n. 2, p. 66-72, 2001.

FERRO PULIDO, Luna Juliana. Garantía de los derechos culturales a luz de las políticas distritales de cultura. 121 f. Disertación (Maestría en Derecho) - Facultad de Derecho, Ciencias Políticas y Sociales, Universidad Nacional de Colombia, Bogotá, D.C., 2013.

GARCÍA CANCLINI, Néstor. Culturas Híbridas: Estratégias para entrar e sair da modernidade. São Paulo: Editora da Universidade de São Paulo, 2008.

GARCÍA CANCLINI, Néstor. Políticas culturales y crisis de desarrollo: un balance latinoamericano. In:___. (org.) Las Políticas Culturales en América Latina. Ciudad de México: Grijalbo, S.A., 1987.
GRUENING, Gernod. Origin and theoretical basis of new public management. International Public Management Journal, v. 4, n. 1, p. 1-25, 2001.

HARVEY, David. El Estado neoliberal. In: (org.) Breve historia del neoliberalismo. Madrid: Ediciones Akal, S.A., 2007.

JANOSCHKA, Michael; HIDALGO DATTWYLER, Rodrigo. La ciudad neoliberal: estímulos de reflexión crítica. In: (orgs.) La ciudad neoliberal. Gentrificación y exclusión en Santiago de Chile, Buenos Aires, Ciudad de México y Madrid. Santiago de Chile: Pontificia Universidad Católica de Chile, 2014

KAPUCU, Naim. New public management: theory, ideology, and practice. In: FARAZMAND, Ali; PINKOWSKI, Jack. (orgs.) Handbook of globalization, governance, and public administration. Boca Raton, FL: CRC/Taylor \& Francis, 2007.

LEVY, Evelyn. O impacto da democratização nas organizações públicas locais. In: FISCHER, Tânia. (org.) Poder local: governo e cidadania. Rio de Janeiro: Fundação Getúlio Vargas, 1993.

LIZARAZO, Jesús Alberto. Descentralización y cultura en Santafé de Bogotá. In: SEMINARIO DISTRITAL 'POLÍTICAS CULTURALES PARA SANTA FE DE BOGOTÁ', 1999, Bogotá, D.C. Memorias. Bogotá, D.C., 1999, p. 58-65.

LÓPEZ MOYA, Waldo. Planificación estratégica y desarrollo urbano. Urbano, n. 21, p. 20-31, 2010.

MENA LOZANO, Úrsula; HERRERA CAMPILLO, Ana Rosa. Políticas Culturales en Colombia. Discursos estatales y prácticas institucionales. Bogotá, D.C.: Mena \& Herrera Editoras, 1994.

OBSERVATORIO DE CULTURAS; DIRECCIÓN DE ARTE CULTURA Y PATRIMONIO. Informe final: Evaluación del Sistema Distrital de Arte, Cultura y Patrimonio. Secretaria de Cultura, Recreación y Deporte, Bogotá, D.C., 2014.

OCHOA GAUTIER, Ana María. Entre los deseos y los derechos. Un ensayo crítico sobre políticas culturales. Bogotá, D.C.: Instituto Colombiano de Antropología e Historia - ICANH, 2003.

RAMÍREZ, Jorge. Instancias de decisión para la definición de políticas para el sector cultural. In: BUSTOS, Marta; NADER, Zaquile; PEÑA, Adriana. (orgs.) Formar para la democracia. Políticas culturales en el Distrito Capital y sus localidades. 
Bogotá, D.C.: Alcaldía Mayor de Bogotá \& Instituto Distrital de Cultura y Turismo, 2003.

REDACCIÓN BOGOTÁ. Bogotá en siete alcaldes. El Espectador, Bogotá, D.C. Agosto 9, 2015.

REPRESENTANTE DE LOS ARTISTAS AL CONSEJO DISTRITAL DE CULTURA. Políticas Culturales para Bogotá. In: SEMINARIO DISTRITAL 'POLÍTICAS CULTURALES PARA SANTA FE DE BOGOTÁ', 1999, Bogotá, D.C. Memorias. Bogotá, D.C., 1999, p. 78-81.

RESTREPO BOTERO, Darío I. Reestructuración capitalista, formas de organización espacial del Estado y nuevas prácticas políticas. In: (org.) La falacia neoliberal. Crítica y alternativas. Bogotá, D.C.: Universidad Nacional de Colombia, 2003.

RIVIĖRE D'ARC, Hélène. Brasil, México e Cuba. Três contextos, três abordagens da descentralização. In: FISCHER, Tânia. (org.) Poder local: governo e cidadania. Rio de Janeiro: Fundação Getúlio Vargas, 1993.

ROBINSON, Mark. From Old Public Administration to the New Public Service: Implications for Public Sector Reform in Developing Countries. Singapore: UNDP - Global Centre for Public Service Excellence, 2015.

RODRÍGUEZ ROMERO, Carlos A. Cultura y calidad de vida. In: SEMINARIO DISTRITAL 'POLITTICAS CULTURALES PARA SANTA FE DE BOGOTÁ', 1999, Bogotá, D.C. Memorias. Bogotá, D.C., 1999, p. 17-21.

RUBIANO PINILLA, Elkin. Entre la apertura discursiva y la restricción participativa: un estudio de caso sobre las políticas distritales de cultura. Revista Comunicación y Ciudadania, n. 1, p. 82-95, 2009.

SPINK, Peter. Descentralização: luto ou luta. In: FISCHER, Tânia. (org.) Poder local: governo e cidadania. Rio de Janeiro: Fundação Getúlio Vargas, 1993.

UNESCO. Conferencia Mundial sobre las Políticas Culturales. UNESCO, París 1982.

VICH, Víctor. Las políticas culturales en debate: lo intercultural, lo subalterno y la dimensión universalista. In: (org.) El Estado está de vuelta: desigualdad, diversidad y democracia.Lima: Instituto de Estudios Peruanos - IEP, 2005.
VIDAL-BENEYTO, José. Hacia una fundamentación teórica de la política cultural. Revista Española de Investigaciones Sociológicas - REIS, v. 16, n. 81 , p. 123-134, 1981.

ZAMORANO, Mariano M.; RIUS ULLDEMOLINS, Joaquim; KLEIN, Ricardo. ¿Hacia un modelo sudamericano de política cultural? Singularidades y convergencias en Uruguay, Paraguay y Chile en el siglo XXI. Revista Europea de Estudios Latinoamericanos y del Caribe / European Review of Latin American and Caribbean Studies, n. 96, p. 5-34, 2014.

\section{Recebido em 21/11/2017 Aprovado em 24/02/2018}

\footnotetext{
I Monica Cristina Moreno-Cubillos. Mestra em Políticas Públicas pela Universidade Federal do Maranhão. Especialista em análise de políticas públicas da Alcaldía Mayor de Bogotá (Colombia). Contato: Monica.m.cubillos@gmail.com
}

II Cooperação entre o governo nacional e municipal, entre municípios, entre regiões ou com governos de outros países.

III Juntas Administradoras Locales.

IV Concejos Locales de Planeación.

V O Sistema Distrital de Cultura é a interação social dinâmica e organizada entre os Agentes Culturais, Instituições e Organizações dos campos de arte, cultura e patrimônio (BOGOTÁ, 2007) que se compõe de cinco subsistemas (Arte, Patrimônio Cultural, Equipamentos Culturais, Grupos Étnicos e Setores Sociais e Etários, e Localidades), acompanhado paralelamente por mesas de trabalho enfocadas em ONGs Culturais, Artesãos, Instituições Educativas e Museus.

VI Estes planos implicam a divisão da cidade em pequenas áreas que agrupam bairros com características sociodemográficas similares. Para sua elaboração é necessário priorizar as estratégias de ação e o programa de investimentos anual e para o período de governo de cada Prefeito. 
VII Impulsado pela administração de Enrique Peñalosa (1998-2000), esta estratégia convocou a participação comunitária através de um concurso que focalizava projetos que só tinham impacto em um determinado bairro ou rua.

VIII ...estimular la acción colectiva a través de una participación organizada, autogestionaria, reuniendo las iniciativas más diversas (de todos los grupos, en lo político, lo social, lo recreativo, etc.).

IX ....ante los posibles efectos de procesos como la homogeneización cultural, el aumento de las desigualdades sociales o la disolución de las identidades colectivas.

$X$ Subdivisão política e territorial da cidade que se define de acordo com as características sociais dos habitantes. Bogotá possui 20 localidades cada uma com as competências e as funções administrativas correspondentes.

XI Para a época era a entidade que tinha como objetivo promover, programar, integrar, coordenar e financiar as atividades culturais e turísticas, da mesma forma que os cenários culturais da cidade que estavam dispersos em diferentes agências. Depois da reforma administrativa de 2007 foi substituída pela Secretaria Distrital de Cultura, Recreación y Deporte (SCRD).

XII ...el director del instituto es a la realidad centralizada de la ciudad, es decir, el gestor debe ser pensado dentro de un proceso de descentralización como gerente o rector o secretario de cultura de la localidad.

XIII ...la generación de organización artística y cultural por la base y particularmente por áreas y disciplinas artísticas, reafirmando que la experiencia vivida en la localidad es posible y deseable de replicar para fortalecer los Sistemas Locales de Cultura, entre otros.

XIV ...consideramos que hay una fuerte homogeneización bajo un modelo único de políticas culturales, perdiéndose la posibilidad de construir a partir de los ritmos y particularidades de cada localidad sus propios procesos. Es decir, se quiere homogeneizar, se quiere trabajar bajo un solo esquema en el ámbito del Distrito y lo que se ha evidenciado es que cada localidad tiene un ritmo propio, una particularidad propia y un desarrollo que hace que se deba construir a partir de esa realidad particular.

XV ...la transferencia de poder, recursos, funciones y capacidad de decisión del centro a las unidades territoriales y en el fortalecimiento de infraestructuras y organizaciones locales que puedan desarrollar eficazmente este proceso.

$\mathrm{XVI}$...en las decisiones que los afectan y en la vida económica, política, administrativa y cultural de la nación como un derecho constitucional.
XVII En general, [...] sólo los actores del Estado tiene la facultad de decidir, porque este poder se los atribuye la ley. Los demás sólo tiene facultades para influir. En el tema de política cultural local, toman las decisiones el Alcalde Mayor, el Concejo, el alcalde local, las UEL [...] y --en menor instancia-las Juntas Administradoras Locales. [...] La alcaldía local es quien toma las decisiones sobre cuáles son los proyectos que se ejecutan con un presupuesto local. [...] Todas las demás instancias y autoridades sólo ejercen presión sobre él. Ni la JAL, ni el Consejo Local de Cultura, ni los Encuentros Ciudadanos toman decisiones relevantes.

XVIII [...] toda política cultural [...] que evada dicha problemática está destinada a contentarse con la pura gestión administrativa que es necesaria -- y, de hecho, puede ser muy eficiente --, pero que no la libra de un entramado de complicidades que pueden terminar conduciéndola a la imposibilidad de generar articulaciones más creativas entre diversos actores sociales. 